\title{
O cotidiano, as crianças, suas infâncias e a mídia: imagens concatenadas
}

\author{
Lisandra Ogg Gomes *
}

\begin{abstract}
Resumo: As práticas das crianças indicam que elas constroem outros significados a partir das articulações que fazem, quando inseridas na vida cotidiana. Nesse sentido, este artigo apresenta reflexôes sobre a condição dinâmica da infância e sobre a forma como as crianças atribuem sentidos para as palavras e as coisas através das suas ações e das suas percepções de mundo. Como referencial, serão considerados os processos de socialização das crianças e as suas múltiplas direçôes e dimensões. São processos sociais que ocorrem entre as crianças e os adultos, entre as crianças e os seus grupos de pares, entre as crianças e a família, a creche, a pré-escola e a mídia.
\end{abstract}

Palavras-chave: crianças; infâncias; mídia; cotidiano.

Daily life, children, their childhood and the media: connected images

Abstratc: Children's practices show that they build different meanings from the connections they establish in their daily routines. This paper presents reflections concerning the dynamic status of childhood and the way children attribute meanings to words and things through their actions and perceptions of the world. Children's socialization processes and their multiple directions and dimensions will be considered as references. They are social processes that occur between children and adults, between children and peer groups and between children and their families, nursery schools, preschool and the media.

Key words: children; childhood; media; daily life.

Para Walter Benjamin (2005, p. 94), “[...] as crianças não constituem nenhuma comunidade isolada, mas antes fazem parte do povo e da classe a que pertencem". Nesse sentido, entende-se que as crianças têm experiências e vivem situações que ocorrem em contextos coletivos caracterizados por sua historicidade e cultura. Assim, a partir das relações estabelecidas em um determinado tempo e espaço, elas fazem desse terreno um campo de representações e interpretações sobre os pensamentos, os signos, as ações e as linguagens que estão presentes no seu cotidiano. E continuamente se deparam com uma com-

* Mestre em Educação pela Universidade de São Paulo, Brasil, e doutoranda em Educação pela Universidade de São Paulo, Brasil. lisandraogg@yahoo.com.br. 
plexa rede de conhecimentos recíprocos e convivências sociais que ultrapassa a família, a creche e a pré-escola.

\section{A vida cotidiana e a infância}

Desde as primeiras reações o indivíduo sente-se governado por algo que está acima dele. São os valores sociais consagrados por uma tradição que se impõe e que é transmitida através das gerações. São os costumes, com seu poder invisível de incluir e guiar cada pessoa no campo das relaçóes sociais. Esse poder interfere nos passos, nos atos, como também atua sobre os sentimentos, as idéias, a fé e a imaginação. Ernst Cassirer (1993, p. 8) diz que o costume é a atmosfera constante na qual o homem vive e existe; ele não pode subtrair-se dela como não pode subtrair o ar que respira.

O costume produz o cotidiano e nele está contido. Já o cotidiano é o que acontece diariamente, e as coisas que aí se passam seguem a ordem da rotina. Então, pode-se dizer que o cotidiano é o dia-a-dia que passa, sem que as coisas pareçam passar (Pais, 2003, p. 28-29). Apesar de parecer que há uma apatia constante na vida cotidiana, é nesse nada de novo que são encontradas condições e possibilidades de resistência que geram as rupturas, pois no que se passou ou no que se passa existe o efêmero, que modifica delicadamente o costume e a rotina.

No cotidiano, o que se passa é a rotina que se configura por ritmos sociais estruturados pela repetição, pela norma e pela regularidade e que garante ao indivíduo um sentimento de segurança. A rotina é feita das atividades realizadas no dia-a-dia, e nela predominam determinados modos de comportamento que são sustentados pela confiança e pela certeza de que a realidade é o que aparenta ser. Sendo assim, o cotidiano manifesta-se como um campo de rituais. Ritos que preservam a continuidade do vivido, que acomodam as contradições entre passado e presente e que fixam eventos, transformando-os de estruturas diacrônicas para sincrônicas (Agamben, 2005, p. 83).

Partindo, por conseguinte, desses conceitos, a vida cotidiana é a vida de todo homem, e todo homem já nasce inserido na vida cotidiana (Heller, 2004, p. 17-21). É no espaço coletivo - social - que cada pessoa participa da vida diária e valoriza nas suas açóes e nos seus discursos os aspectos da sua individualidade e da sua personalidade: sua capacidade intelectual, suas habilidades manipulativas, seus sentimentos, suas paixōes e suas idéias. Através da rotina e na convivência com outros, o indivíduo experimenta e aprende os costumes e os valores do seu espaço e do seu tempo.

Cada pessoa que vive em sociedade tem em si a essência da humanidade - a consciência de nós. E, ao apropriar-se da cotidianidade da sua época, também se apropria do passado da humanidade e das trajetórias coletivas. Portanto, o 
indivíduo é, ao mesmo tempo, produto e expressão das relações sociais; é produtor, sucessor e conservador do processo humano; é um ser genérico.

Contudo, há diversos e diferentes elementos que distinguem as pessoas, pois, como analisa Hannah Arendt (1987, p. 188), se as pessoas fossem todas iguais, elas seriam incapazes de compreender-se entre si e de compreender os seus ancestrais ou de fazer planos para o futuro e prever as necessidades das gerações vindouras. Se as pessoas não fossem diferentes, elas não precisariam do discurso ou da ação para se fazerem entender. Apenas com simples sinais e sons poderiam comunicar suas necessidades imediatas e idênticas.

Significa que o indivíduo também tem em si as necessidades do $e u-t e m$ fome, sente dores (físicas ou psíquicas), tem afetos e paixões. Ele tem uma trajetória individual, manifesta-se, faz referências e apontamentos sobre seus desejos e objetivos. Portanto, é um ser particular. Isso expressa que o eu e o nós - o indivíduo e a sociedade - não são termos contraditórios, mas termos complementares que se mesclam e compóem uma síntese integrada - um humanogenérico (Heller, 2004, p. 20-21) -, pois cada um é ao mesmo tempo um ser em si e um ser no outro.

Não há um paradigma para fundamentar a relação entre o particular e o genérico. $\mathrm{O}$ que existe são distintos princípios que se combinam, pois essas abordagens não estão em conflito, mas, ao contrário, estabelecem correspondências ininterruptas. Nesse caso, o particular e o genérico não se excluem, como também não se referem a coisas diferentes. Portanto, não há como estudálos separadamente, pois eles se relacionam e se submetem sucessivamente um ao outro, embora sem o imperativo da referência. Norbert Elias e John Scotson (2000, p. 184) alertam que fundamentar a reflexão em um único indivíduo, como se ele fosse independente de todos os demais, sem levar em consideração suas relações mútuas, é partir de um indivíduo fictício e supor que a vida social se baseie em um contrato firmado por indivíduos que, antes dele, viviam sozinhos na natureza ou juntos numa descoberta absoluta. De modo contrário, dizer que os indivíduos apenas existem em sociedade é considerar somente a pluralidade e a interdependência entre eles. Mas, por sua vez, afirmar que as sociedades são irredutíveis significa que nem se pode explicá-las em termos que insinuem que elas tenham algum tipo de existência independente dos indivíduos, nem em termos que insinuem que os indivíduos, de algum modo, existam independentemente delas. Parece que há "[...] um certo horror de que as 'sociedades', ou, para dizê-lo de maneira mais dúbia, as configurações que os indivíduos formam entre si exercem algum poder sobre esses indivíduos e restringem sua liberdade" (Elias; Scotson, 2000, p. 185).

Considera-se que entre o individual e o social há constantes interações, interposições e transformações - com práticas e saberes diferenciados, mas em 
espaços e tempos situados que percorrem o dia-a-dia de crianças, jovens, adultos e idosos e que colocam à mostra o transitório e o estável da vida cotidiana.

Toda pessoa é criada em um contexto cotidiano em que aprende a usar a linguagem comum, objetos artificiais e adquire um certo conhecimento de formação que inclui fatos e valores, assim como a disposição de obedecer normas e regras. Embora os sistemas invadam a vida cotidiana, embora o discurso científico exerça enorme influência sobre nossas idéias de boa vida, embora os mundos de vida (isto é, a soma total dos padrōes culturais e normativos partilhados) se tornem pluralistas e difusos, a vida cotidiana ainda se mantém como uma esfera separada. Os conflitos que ocorrem nessa esfera fazem parte de nossas experiências de vida básica e podem desenvolver em nós necessidades pelas quais estamos dispostos a fazer reivindicaçōes (Heller; Feher, 2002, p. 53, grifos do autor).

Isso indica que cada indivíduo elabora uma maneira própria de decidir sobre o seu cotidiano, mas que ele também tem em si os costumes, as normas, as relações de interdependências com as outras gerações e as condições dadas pelo coletivo. $\mathrm{Na}$ medida em que cada um tem em si o plural e o singular, as sensações, as comparações, as interpretações, os julgamentos, as reflexôes e as escolhas são incertos para os outros. Entretanto, essas práticas devem transcorrer no espaço daquilo que é esperado. A vida cotidiana é um processo de conhecimento a partir das relaçóes entre o particular e o genérico, que então se convertem em significados. Os processos recíprocos que ocorrem entre o indivíduo e a sociedade produzem ações, discursos e representaçôes que estão presentes na vida diária e geram um movimento entre o saber e o fazer esperado ou imprevisto. Para Beatriz Sarlo (1997, p.104),

[...] sempre há pessoas que andam de um lado para o outro, sempre há uma história que está se perdendo e uma memória que se procura (ou não se procura) constituir-se, sempre há sujeitos cindidos que não chegam a reconhecer-se em algum lugar, sempre esses sujeitos dão um jeito de usar o espaço construindo novos sentidos, seja ressemantizando práticas ou inventando práticas novas, sempre há algo de deriva e algo de determinação, sempre há algo que passa ao privado e algo que se torna público em novos usos.

É uma realidade que existe a partir das interpretações e das significações que cada um faz. É um presente que, na maioria das vezes, mostra-se ainda camuflado e escondido - como uma sala de espelhos onde os reflexos vistos ainda estão distorcidos e sem formas aparentes. 
Os apontamentos feitos até aqui permitem considerar que todos os indivíduos -independentemente de idade, etnia, sexo ou raça - têm fundamental importância para que o particular e o genérico possam configurar a vida cotidiana. Portanto, todas as geraçooes envolvidas nos processos cultural, histórico e social têm imenso valor. Ademais, cada fase da vida tem suas especificidades, suas características e sua atuação. E é nesse sentido que a infância é uma das categorias essenciais que compõem o cotidiano e as gerações. A infância transforma a história, pois ela é nascimento, é brincadeira, é jogo e é transitoriedade. Sem a infância a vida cotidiana estagnar-se-ia apenas diante do rito, da sincronia e do visível.

A infância, as outras gerações e as instituições compõem, organizam e reproduzem os variados tempos e espaços sociais a partir das práticas sociais. Se uma criança nascesse conhecedora das normas e das convenções que organizam a vida diária, não haveria rupturas e interdições, e sua atuação sobre as coisas e as palavras seria destituída de história. Mas, na medida em que a criança precisa entrar na vida cotidiana, aprender a usar os artefatos culturais, compreender as regras, os valores, os costumes, as linguagens e os contextos, ela passa a atuar sobre a cultura, a natureza e a história. É nesse sentido que a infância é imprescindível para a vida cotidiana e para a sociedade.

Manuel Pinto (2000, p. 81) considera que a infância emerge como realidade social, porém é uma realidade ainda pouco conhecida. De acordo com esse autor, é uma realidade que produz, em certa medida, a própria sociedade. Então ele pergunta:

Quem são, afinal, as crianças? Em que diferem e se assemelham relativamente aos mais velhos? O que identifica e distingue esse grupo social, internamente e relativamente a outros grupos? Que práticas e que representações sociais existem relacionadas com as crianças, quer específicas das próprias crianças quer específicas dos adultos? E como variam tais práticas e representações relativamente a dimensōes como a posição social, o sexo, a zona geográfica, as atividades dos pais, etc.? Como é que as crianças vêem o mundo em que vivem e como é que vêem a sua condição de crianças? Que é que fazem quando entregues a si mesmas e em condiçôes de poderem organizar e gerir o tempo e o espaço? Como é que são vistas: mais como agentes activos ou mais como seres passivos perante a sociedade e a vida adulta? Será que existem expressões culturais próprias das crianças? Que marcas podem ser identificadas no espaço social, resultantes da presença ou da resposta às necessidades das crianças? (Pinto, 2000, p. 81). 
Essas múltiplas interrogações indicam que pouco se sabe sobre os sistemas protagonizados pelas crianças, ou seja, que a palavra da infância é pouco escutada, que pouco se sabe sobre os modos de pensar das crianças e de seus universos específicos. Para entender a atuação e a participação das crianças na sociedade é preciso olhar para a realidade social e para a vida diária delas, considerando o ponto de vista das crianças, e, sobretudo, é preciso olhar para os seus mundos sociais. Para tanto, é importante partir de uma posição sociológica que considere, inicialmente, pelo menos três pressupostos: as crianças como atores ${ }^{1}$ sociais, os condicionantes do sistema social e as incidências do mundo da infância no sistema social.

\section{As crianças e suas infâncias}

A infância é sempre presente na ordem social. Jens Qvortrup (2004) indica que a infância é uma categoria permanente e essencial na estrutura das sociedades. Ela se distancia de cada criança em particular por se dirigir a uma noção formal e subjetiva. Todavia, os princípios da infância estão suficientemente próximos da realidade de cada criança. Nesse caso, cada uma delas, no curso da sua infância, manifesta-se, faz referências, tem experiências, vivências e reflexões a partir de suas necessidades, de seus interesses e de sua realidade cotidiana. Sendo assim, a infância é uma categoria permanente, na medida em que está sempre pronta a abraçar novos grupos de crianças. Contudo, é uma fase que não se conserva inflexível, porque há diversos parâmetros - econômico, social, político, cultural, tecnológico, ideológico, etc. - que interferem e influenciam nos modos como as crianças e os adultos vivem e entendem esse momento da vida. Nesse caso, não será em uma singular criança que se manifestará a essência da infância, mas nas circunstâncias nas quais vivem todas as crianças e nas formas e nas transformações estruturais das infâncias.

As circunstâncias impõem-se, no sentido em que não são, pelo menos em parte, definidas e escolhidas pelos agentes, mas estes encontram múltiplas formas de se relacionar com elas: ora submetendo-se, ora desafiando, reinterpretando e recriando essas circunstâncias, em função da respectiva posição, dos recursos e dos eventos (Pinto, 2000, p. 52).

1. O conceito de ator aqui é utilizado a partir da Sociologia da Educação de Pierre Bourdieu. Segundo Cláudio Marques N. Nogueira e Maria Alice Nogueira (2002, p. 20), para o autor francês, o ator não é nem o indivíduo isolado, consciente e reflexivo, nem o sujeito determinado, mecanicamente submetido às condições objetivas em que ele age. Para ele, cada "indivíduo passa a ser caracterizado por uma bagagem socialmente herdada" (Nogueira; Nogueira, 2002, p.20). Bagagem com certos componentes objetivos, externos ao indivíduo, e subjetivos. 
A infância tem uma dimensão natural e social e, portanto, sua amplitude vai além da necessidade de proteção, educação e cuidado que as crianças apresentam. É uma fase da vida que não pode ser considerada apenas pelo que está por vir. Todavia, essa é uma idéia ainda recorrente e, geralmente, a infância é reconhecida pelos adultos como a idade do não-domínio da razão e da linguagem. Nos discursos e nas práticas sociais ainda percorre uma imagem mitificada acerca das crianças e uma concepção homogênea a respeito da infância. Aos olhos dos adultos os códigos infantis são considerados também incompletos. Porém, é porque há a instabilidade e a idéia de ser uma fase incompleta que as crianças e suas infâncias têm a possibilidade de cursar por diversos caminhos. As crianças se adaptam às dinâmicas sociais que circunscrevem a vida cotidiana, mas também produzem, reproduzem, elaboram e transformam de forma sensível as suas rotinas. Isso se dá a partir da sua inserção em um contexto social de interações e interdependências - embora muitas das atuações das crianças não incidam diretamente na estrutura social vigente.

A vida de crianças e a de adultos misturam-se, pois todos compartilham circunstâncias, práticas e atividades sociais. Todavia, há estatutos sociais rígidos e definidos que especificam o que é próprio de cada categoria. Esses elementos não devem ser usados para conferir maior importância a uma das categorias, pois as especificidades da vida cotidiana infantil e da vida cotidiana adulta não podem ser comparadas, apenas compreendidas a partir das interaçôes e dos seus códigos particulares. Para Helga Zeiher (2003, p. 114), as relaçōes entre gerações dão-se, antes de tudo, na vida cotidiana. E, considerando os processos sociais e históricos, a relação entre a criança e o adulto tem muitas e várias restriçôes, além de haver aspectos diferentes em relação ao modo como as crianças podem e devem atuar no cotidiano.

Mesmo com espaços e tempos adequados e determinados pelos adultos ${ }^{2}$, a atuação das crianças na vida cotidiana vai muito além do que foi determinado. Sendo assim, elas não ficam à espera somente do que os adultos lhes destinam. De modos diversos, participam ativamente, pois vivem em grupos, apreendem os elementos da vida sociocultural e exercitam um habitus ${ }^{3}$ de aprendizagens indispensáveis para a sua vida diária. A partir das relaçōes sociais diversificadas, as crianças - conscientes ou não dos seus saberes e fazeres - propõem variações no interior de um mesmo sistema de regras geradas pelos adultos, pelas instituições ou por elas mesmas na interação com seu cotidiano.

2. Como, por exemplo, o afastamento das crianças da vida profissional, a proteção e a freqüência às instituições de educação.

3. "[...] habitus, sistema de disposições inconscientes que constitui o produto da interiorização das estruturas objetivas e que, enquanto lugar geométrico dos determinismos objetivos e de uma determinação, do futuro objetivo e das esperanças subjetivas, tende a produzir práticas e, por esta via, carreiras objetivamente ajustadas às estruturas objetivas" (Bourdieu, 1987, p. 20 I). 
Para Ana Bondioli (2004, p. 126), são regras, módulos de comportamento, determinações do que é permitido, apropriado, adequado, oportuno, correto e conforme que se encontram como que "incorporados" nos diferentes "encontros" dos quais o indivíduo participa. E, ao participar das relaçôes sociais, a criança aprende suas regras - as variantes e as fixas -, os aspectos importantes e os irrelevantes. É uma relação mútua e de interdependência que as crianças vivem com os adultos. Sendo assim, nenhuma dessas categorias pode existir sem a outra e, conseqüentemente, as mudanças que ocorrem em uma delas afetam e desencadeiam mudanças na outra.

Considerados esses argumentos, indica-se que as crianças são agentes dos seus atos - são atores ${ }^{4}$-, pois percebem, interpretam e dão significados diversos às relações que percorrem as maneiras de fazer a vida diária. Do mesmo modo, a receptividade e a intimidade entre crianças, adultos e instituições consentem relações de dependências recíprocas, interposições, manifestações, interpretações e conhecimentos sobre o que foi produzido. Essas trocas possibilitam novas produções diante do que provoca a curiosidade. São olhares distintos que resultam em linguagens, significados e pensamentos diversos.

Percebe-se, assim, que as condições de vida das crianças não são estabelecidas apenas pelos processos biológicos e pelos desenvolvimentos individuais. Para além desses processos, é preciso identificar e entender em que condições materiais elas estão agindo, conhecer suas condições concretas de vidas. Caracterizar as reais condições de vida das crianças - condição de classe, sexo, pertencimento étnico - abre caminho para intervir no sentido de interrogar os constrangimentos constitutivos dos mundos da infância (Quinteiro, 2005, p.139-141). Isso consiste em conhecer e aproximar-se das complexas relações que as crianças estabelecem com o resto da sociedade e entender uma dinâmica que está posta, mas que ainda não foi compreendida.

Roger Bastide escreveu, no prefácio do trabalho de Florestan Fernandes (2004, p. 229), que entre o mundo adulto e os das crianças parece haver "[...] um mar tenebroso, impedindo a comunicação". E ele pergunta:

Que somos nós, para as crianças que brincam ao nosso redor, senão sombras? Elas nos cercam, chocam contra nós; respondem às nossas perguntas, num tom de condescendência, quando fingimos interessar-nos por suas atividades; mas sente-se, perfeitamente, que, para elas, somos como os móveis da casa, parte do cosmos exterior, não pertencemos a seu mundo, que tem seus prazeres e seus sofrimentos. E nós, adultos, vivemos também dentro de nossas próprias fronteiras, olhamos as crian-

4. Elas são produtos da sociedade, difusoras, produtoras e reprodutoras das estruturas sociais. 
ças brincar, repreendemo-las quando fazem muito barulho, ou, se deixamos cair sobre seus divertimentos um olhar amigo, não é para eles que olhamos, mas, através deles, para as imagens nostálgicas de nossa infância desaparecida. (grifos meus).

Para conhecer as crianças, é essencial pensar as formas de interdependência, as funções e a estrutura na qual se inserem esses sujeitos, o modo como se relacionam nos seus grupos de pares, nos seus grupos de brincadeiras e com os demais elementos que compóem a sociedade. Conhecê-las significa entender como vivenciam suas infâncias, como atuam e compartilham experiências e sentidos com outras crianças e adultos.

Norbert Elias e John Scotson (2000, p. 133) dizem que a "[...] identidade coletiva e, como parte dela, o orgulho coletivo e as pretensões carismáticas grupais ajudam a moldar a identidade individual, na experiência que o sujeito tem de si e das outras pessoas". É logo no início da vida que as crianças participam de um sistema simbólico no qual são imprescindíveis as trocas. Nessa relação elas buscam compreender aquilo que perpassa seu tempo e espaço e, concomitantemente, adaptam-se. Assim, deixam marcas sutis e dão novos contornos aos processos sociais, culturais, ideológicos e econômicos. Desse modo, a cultura não é apenas transmitida às crianças, porque elas produzem, apreendem, imitam e reproduzem, a seu modo, a sua realidade.

Posto isto, afirma-se que, além de serem atores, as crianças também são autores, no sentido de que modificam de modo sensível os modelos originais dos discursos e das práticas. As decisões que tomam estão ajustadas aos pressupostos estabelecidos - o genérico, essa atmosfera permanente na vida de cada indivíduo -, mas isso não impede que modificaçōes em seus espaços e tempos ocorram devido aos seus desejos e interesses, aos seus objetivos e às suas interpretações.

\section{A imitação e as experiências}

A imitação é elemento fundamental para que as crianças possam interpretar seu contexto e sua rotina, além de atuar em seus espaços e tempos. Através das relaçôes de troca, elas significam a vida cotidiana por meio da experiência, da vivência, da aprendizagem, da interpretação e da criatividade.

Todo indivíduo faz uso da imitação e, não de modo diferente, as crianças também se valem dos modelos. São diversas as situações que acontecem no cotidiano e, para adequar-se aos novos contextos, a capacidade de inovar é essencial. Noan Chomsky (1976, p. 76) já havia considerado que, com a imitação, pode-se comparar e combinar sensações individuais e interpretar a experiência em função dos objetos, das suas propriedades e dos acontecimentos dos 
quais se participa. Citando Géraud de Cordemoy (1677, p. 17), afirma que a imitação na linguagem não pode ser compreendida como algo mecânico, pois, "Falar não é repetir as mesmas palavras que nos chegam aos ouvidos, mas [...] é proferir outras a propósito daquelas" 5 .

$\mathrm{Na}$ vida cotidiana, as crianças aprendem, através da imitação e da identificação, uma série de regras estáveis que asseguram o previsível, mas também aprendem que podem ocorrer variações no interior de um sistema de regras e que essas alteraçóes podem ser ocasionadas por elas (Corsaro, 2003, p. 50). Por meio da interação, as crianças tentam compreender as distinções da rotina e, igualmente, revelam seus conhecimentos e seus interesses para outras crianças e adultos. É uma dinâmica entre sujeitos e entre estes e os objetos. Nessa relação elas adotam como modelo aquilo que circula na sua realidade próxima, mas, simultaneamente, compóem algo diverso, pois acrescentam, interpretam e dão novos sentidos ao que estão imitando. Portanto, não é uma imitação servil, como tampouco é uma imitação condicionante, que nega a existência dos processos mentais. Ao contrário disso, a imitação que aqui se deseja sublinhar é o resultado das interpretações e das composições de práticas e discursos que carregam em si o sentido da inovação e da criatividade.

Essa relação pode ser mais bem compreendida nos jogos e nas brincadeiras. A brincadeira de faz-de-conta, por exemplo, é a maneira de agir e refletir sobre as experiências e as sensaçōes da vida cotidiana. Quando as crianças imitam práticas e discursos que circulam no seu meio, elas não fazem referência direta a uma pessoa ou a uma idéia específica. Nas suas brincadeiras, o que predomina é o genérico. Para Florestan Fernandes (2004, p. 247), as brincadeiras como papai e mamãe ou polícia, por exemplo, são abstrações que as crianças fazem, nas quais desempenham tais funçōes e preservam apenas o conteúdo social que as relações entre indivíduos implicam. Como o autor explica, nessas brincadeiras não se pode reconhecer o pai da criança - Pedro, ou Paulo, ou Maria -, mas somente são identificadas as representaçōes que as crianças têm a respeito dessa função social. Essas imitaçôes não são reflexos exatos das atividades dos adultos, ou seja, não se trata de uma imitação servil. O que predomina é o genérico, mas o particular não deixa de atuar, porque cada criança compõe sua representação tendo por modelo as vivências e as experiências da sua realidade. Portanto, nas brincadeiras ou nos jogos as crianças acrescentam o seu humano-genérico - para utilizar o conceito de Agnes Heller (2004, p. 20) -, ou seja, aquilo que elas têm de si e aquilo que elas têm do outro.

5. "Parler n'est pas répéter les mêmes paroles dont on a eu l'oreille frappée, mais [...] c'est en proférer d'autres à propos de celles-là" (Cordemoy, 1677, p. 17). 
Nesse sentido, quando as crianças imitam algo, não necessariamente modificam todo o modelo original; ao contrário disso, elas precisam considerar e respeitar as regras que já foram estabelecidas socialmente. É a partir dos pressupostos estabelecidos que elas podem acrescentar elementos que permitam produzir ou compor algo novo e específico. Dessa forma, a inovação, quando da imitação, percorre um trajeto que vai da integração e da comparação das experiências subjetivas passadas à reorganização dos modelos dados objetivamente. Conseqüentemente, imitação é inovação, e a criação e o respeito às regras caminham lado a lado (Brougère, 1998, p. 114-115). Portanto, ser criativo não significa ser original, no sentido de fazer sempre algo novo e inusitado.

A criança, ao imitar, vale-se do seu contexto, dos recursos que tem, da sua posição social e da sua história. Com esse leque de opções ela constrói suas interpretações, confere valor aos objetos, combina discursos diversos - criticando-os ou aceitando-os. A cultura e a natureza servem como modelos. Zygmunt Bauman (1998, p.170) indica a cultura como um modelo que se desloca por rotas impossíveis de prever, pois as ações humanas são sempre novas. São modelos únicos, por mais que sejam cópias.

Os modelos não existem de nenhum outro modo, a não ser no processo de contínua e inescapável transformação. Com a passagem do tempo, as transformações atingem diversos graus de visibilidade, mas as mudanças são esparsas - e, no momento que adquirem proeminência, assim como a novidade que se torna proeminente, elas são imprevisíveis, já emergem de uma profusão de minúsculos imperceptíveis e esparsos desvios (Bauman, 1998, p.170).

Essa possibilidade de criar outras formas de interpretação, de desencadear novos olhares e de compor diferentes caminhos é o que permite a transitoriedade na vida cotidiana. E é nesse sentido que a infância revela a imperfeição do adulto e a invenção do possível. Solange Jobim e Souza (2005, p. 98) diz que a criança, ao construir seu universo particular no interior de um universo maior reificado, é capaz de resgatar uma compreensão polifônica do mundo, devolvendo, através do jogo que estabelece na relação com os outros e com as coisas, os múltiplos sentidos que a realidade física e social pode adquirir. Por isso, é preciso continuar a enriquecer a humanidade com novos mitos e utopias.

Contudo, a experiência contemporânea tem seu correlato na palavra, ou seja, na razão. Walter Benjamin (2005, p. 21), no ensaio intitulado "Experiência", escreve: 
Travamos nossa luta por responsabilidade contra um ser mascarado. A máscara do adulto chama-se "experiência". Ela é inexpressiva, impenetrável, sempre a mesma. Esse adulto já vivenciou tudo: juventude, ideais, esperanças, mulheres. Foi tudo ilusão. - Ficamos, com frequêencia, intimidados ou amargurados. Talvez ele tenha razão. O que podemos objetar-lhe? Nós ainda não experimentamos nada.

$\mathrm{Na}$ continuação desse ensaio, o autor ainda aponta que, para os adultos, a juventude e a infância são épocas das doces asneiras que precedem a longa sobriedade da vida séria. "Assim é a vida, dizem os adultos, eles já experimentaram isso" (Benjamin, 2005, p. 22).

Para Hannah Arendt (1987, p. 106), realmente os adultos já tiveram outras experiências em comparação com as crianças. Eles já consumiram tantas coisas que adquiriram familiaridade com o mundo e com seus costumes, sabem os hábitos de intercâmbio entre os homens e as coisas, bem como entre os homens e os homens. O agir em seu espaço e tempo proporcionou-lhes esses saberes. E, embora a infância seja considerada como a época das doces asneiras, pois é colocada em oposição ao trabalho adulto, os elementos que a configuram são fundamentais para sua constituição e para a história de cada geração. O lúdico e a orientação hedonista são os atributos que identificam a infância. São esses dois elementos que caracterizam a condição de ser criança (Zeiher, 2003, p. 123). Nesse sentido, as brincadeiras, os jogos e o prazer são elementos essenciais para a constituição do particular e do genérico, pois permitem romper com o continuum da história e com as significaçóes postuladas tanto pela vida cotidiana adulta quanto pelas instituiçōes. Assim sendo, o brincar, o jogar e o prazer contribuem para uma freqüente renovação das relações sociais e culturais.

Quando as crianças brincam ou jogam, elas se relacionam com os artefatos, com os costumes e com os valores da sua cultura; elas anulam o passado e o presente, criam e atuam em um tempo diacrônico e sincrônico, sabem que o que fazem é brincar e jogar e deixam-se tomar por esse momento. Nas brincadeiras de faz-de-conta ou nos jogos, por exemplo, elas produzem uma realidade diferente, mas ao mesmo tempo semelhante à vida cotidiana. É uma atuação que permite o conflito, a interação e as linguagens.

A partir das experiências ${ }^{6}$ que tiveram, nas brincadeiras e nos jogos, as crianças dominam, paralisam e destroem por um instante a rotina da vida cotidiana. Nessa atuação há uma experiência imediata e disponível, isto é, o prazer.

6. "Onde há experiência no sentido estrito do termo, entram em conjunção, na memória, certos conteúdos do passado individual com outros do passado coletivo" (Benjamin, 1994, p. 107). 
Entretanto, o riso, o lúdico, o prazer e o divertimento são cabíveis somente dentro de certos tempos e espaços, pois a vida adulta está pautada em princípios racionais, e o prazer é uma recompensa a ser buscada em um momento futuro.

As crianças não adiam o prazer; ao contrário, buscam-no nas suas brincadeiras e nos jogos e, para isso, utilizam as brechas, modificam e rompem ainda que momentaneamente - com os gostos, as crenças, as regras e os valores culturais. Assim, elas vivenciam as regras e têm experiências imediatas, diversas e únicas que alteram e destroem as significaçôes da vida cotidiana.

Para Walter Benjamin (1984, p. 77), as crianças gostam de brincar e sentem-se irresistivelmente atraídas pelos destroços que surgem da construção, do trabalho no jardim ou em casa, da atividade do alfaiate ou do marceneiro. Nesses destroços elas reconhecem o rosto que o mundo das coisas volta exatamente para elas, e só para elas. A intenção delas não é apenas imitar as obras dos adultos, mas estabelecer entre os mais diferentes materiais, através daquilo que criam em suas brincadeiras, uma nova e incoerente relação. É assim que as crianças formam seu próprio mundo das coisas, com um mundo pequeno inserido em um maior.

A imitação passa a ser autoria na medida em que as crianças fazem novos arranjos e interpretaçôes a partir daquilo que têm por modelo. E considerá-las autoras é algo fundamental para o conceito de infância, porque consolida novas formas de entender e compreender os modos de pensar essa fase da vida e desarticula o referencial de um sujeito que está por vir. Conseqüentemente, desfaz-se a idéia de que as crianças sabem menos que os adultos e define-se que elas sabem outra coisa, porque têm outras perspectivas. O efêmero que está implícito na infância permite transformar, desfazer o contínuo e acrescentar outras acepçôes - novas ou não - àquilo que faz parte do cotidiano desses sujeitos, mas não necessariamente esses outros olhares significam algo sempre melhor. Entende-se que a história de uma pessoa não é feita de progressos consecutivos, mas é feita mediante a adição de uma série de "novos começos". São experiências que se agrupam, que são demolidas e refeitas umas sobre as outras, como uma "identidade de palimpsesto" (Bauman, 1998, p. 36).

As crianças, a creche, a pré-escola e a mídia: relações cotidianas

Os processos de socialização dos indivíduos ocorrem em espaços plurais e agregam diferentes referências e relações sociais. No caso da infância, a família e a escola de Educação Infantil atuam como instâncias socialmente reconhecidas no processo de socialização das crianças. No entanto, a mídia representa mais uma instância que está presente na vida delas. 
A família é uma esfera privada, o primeiro e principal agente no processo de socialização das crianças. Maria da Graça Jacintho Setton (2002, p. 111) aponta que a família pode ser entendida a partir de dois enfoques. O primeiro, o psicológico, considera a família como o espaço de relações identitárias e de identificação afetiva e moral. O segundo, partindo da teoria de Pierre Bourdieu, julga a família responsável pela transmissão de um capital econômico e cultural.

$\mathrm{Na}$ esfera pública, a creche e a pré-escola são ambientes preparados, realizados e projetados para as crianças. Esses espaços também promovem a socialização das crianças, que ali se encontram com outras. As experiências e as vivências que têm possibilitam que conheçam códigos, signos e símbolos pertencentes à cultura infantil e à cultura na qual estão inseridas - e atribuam-lhes significados. Para Anete Abramowicz (2003, p. 14), com a creche e a pré-escola a criança passou a ter um espaço próprio de educação para o exercício da infância.

Essas duas instâncias envolvem a criança em um processo de socialização, ao transmitir um patrimônio de crenças e valores, de atitudes e comportamentos e ao possibilitar interações que ocorrem por razão de contextos diversos. Contudo, a vida das crianças não se restringe a essas duas esferas. E, antes mesmo de participar dos espaços coletivos de educação, as crianças já se relacionaram com outros adultos - avós, tios, vizinhos, etc. - e com outras crianças - irmãos, primos e colegas -, assim como já perceberam e compararam as imagens e os textos que circulam pela mídia. Isso significa que, antes de participarem dos espaços da infância, as crianças já tiveram contato com o rádio, com o cinema, com as imagens nas revistas e nos jornais e, principalmente, com a televisão, pois os meios de comunicação fazem parte da cultura na qual estão inseridas.

$\mathrm{O}$ acesso a esse conjunto de elementos permite às crianças outras experiências e outros modos de conhecer; permite ainda uma relação virtual ${ }^{7}$. De modo geral, pode-se dizer que a socialização das crianças começa pela família e vai progressivamente alargando-se - por exemplo, com a vizinhança, a mídia, a entrada na creche, na pré-escola e assim por diante. Portanto, a socialização das crianças não é caracterizada por uma estrutura dual - família e escola -, pois há "uma nova ordem social regulada por um universo cultural amplo e diversificado, embora fragmentado" (Setton, 2002, p. 109).

7. Manuel Castells (1999, p. 395) define o virtual como símbolos formadores da prática com sentidos que escapam à rigorosa definição semântica. "É um sistema em que a própria realidade (ou seja, a experiência simbólica/material das pessoas) é inteiramente captada, totalmente imersa em uma composição de imagens virtuais no mundo do faz-de-conta, no qual as aparências não apenas se encontram na tela comunicadora da experiência, mas se transformam em experiência". 
As descentralizações culturais produzidas pela mídia com a ampliação das formas de reprodutibilidade técnica ${ }^{8}$ conceberam novos regimes do sentir e do saber. Provocaram recomposiçôes na forma de conhecer e de se informar. As experiências e as vivências que compõem esse momento de vida das crianças e que farão parte da história delas agora excedem as instâncias tradicionais. Isso significa que "a educação no mundo moderno não conta apenas com a participação da escola e da família. Outras instituições, como a mídia, despontam como parceiras de uma ação pedagógica" (Idem). É pela televisão, pelo jornal ou pelo rádio, por exemplo, que muitas pessoas têm acesso às produções literárias, musicais, teatrais, da dança, pictóricas, escultóricas ou cinematográficas. "Os fascículos culturais e as revistas de moda e decoração vendidas em bancas de jornais e supermercados levam as inovações literárias, plásticas e arquitetônicas aos que nunca visitam as livrarias nem os museus." (García Canclini, 2000, p.87).

Nesse sentido, as experiências e as vivências virtuais e reais consentem outras formas de olhar e de compreender o tempo e o espaço. Essa relação concede às novas geraçôes um contexto histórico distinto, ao abranger outras dimensões do conhecimento humano - com o contato vivido e o contato virtual.

Todavia, ainda há olhares dicotomizados sobre a mídia - apocalípticos ou integradores ${ }^{9}$ - que permitem apenas constataçôes e repetiçóes de julgamento comum. Compreende-se que a relação que as crianças estabelecem com a mídia é complexa e ultrapassa esses dois princípios. Sendo assim, tal relação deve ser analisada a partir da correlação com outros fatores que circunscrevem a vida diária infantil. Além disso, parte-se do pressuposto de que as crianças não recebam passivamente aquilo que esse aparato veicula, porque elas interpretam, atribuem significados e filtram o que circula pela mídia e, assim, inovam a partir de suas experiências e vivências reais e virtuais.

Ver televisão, escutar música ou assistir a um filme são práticas do cotidiano infantil que ocorrem juntamente com outras práticas - como brincar, ir à creche, à pré-escola, freqüentar a igreja e participar de festas. O que é apontado aqui é a necessidade de caracterizar as condiçôes reais de vida das crianças e os modos como vivem suas infâncias, ou seja, o que fazem com aquilo que vêem na mídia. Como interpretam e usam os discursos, as práticas e as expressões que são transmitidas pela televisão, pelo rádio, pela internet ou pelo cinema

8. "Multiplicando as cópias, elas transformam o evento produzido apenas uma vez mais num fenômeno de massa. Permitindo ao objeto reproduzido oferecer-se à visão e à audição, em qualquer circunstância, conferem-Ihe atualidade permanente." (Benjamin, 1975, p. I4).

9. De acordo com Umberto Eco (1970), a concepção apocalíptica entende os meios por seu caráter manipulatório e coercitivo; a concepção integrada aceita a importância dos meios por possibilitar a participação social. 
nos seus grupos de pares, nas brincadeiras e no coletivo social. O que se deseja compreender é como as crianças mesclam os tecidos híbridos e mutáveis das culturas nas quais participam.

Manuel Pinto (2000, p.71-72) avalia que as crianças vêem televisão cada vez mais cedo, dominam com maestria o controle do aparelho desde tenra idade e consomem com interesse programas não apenas destinados a elas, mas também aqueles dirigidos aos adultos. Para ele, ver televisão, por exemplo, não é um ato individual, mas social, porque os meios se encontram na dimensão do cotidiano infantil e o que circula por esse aparato suscita e alimenta as interaçóes infantis.

Pela mídia as crianças têm acesso a "[...] inumeráveis situações, informações e problemas em torno da vida social e natural, próxima e distante, sobre diversas facetas e dimensões do tempo e do espaço, numa linguagem complexa que resulta de uma combinação de várias linguagens" (Pinto, 2000, p. 266). E se elas atribuem significado ao que circula pela mídia é porque elas estabelecem uma relação muito íntima com aquilo que faz parte do seu cotidiano. Ao falar sobre o que viram na televisão, no cinema ou sobre algo que escutaram pelo rádio, participam na sociedade, interagem com os demais, adaptam-se, questionam, argumentam e percebem que há outros matizes sociais e culturais. Essa é uma das maneiras pelas quais elas conhecem o mundo a partir de vivências e experiências comuns - virtuais e reais - que se expandem e se transformam com e no seu grupo.

Nessas interaçôes, elas tentam descolonizar o pensamento e decodificar as tensões, quando misturam ou acrescentam a suas brincadeiras ou conversas as representações e o conhecimento sobre o mundo que observam em casa, na creche ou na mídia. E essas novas interpretaçōes permitem a não-estagnação da cultura. Contudo, é natural que o diferente encontre certa resistência, pois a estabilidade é princípio que fundamenta a cultura, é o que garante a lógica para o que já está posto. Mas, diante de um campo plural e heterogêneo, as crianças encontram diversos caminhos que se interconectam e, a partir da atuação e da reação, elas deslegitimam a idéia de que há uma única infância e uma única criança. Assim, mostram que as ações e as representaçôes que produzem e reproduzem percorrem espaços e tempos localizados.

\section{Referências bibliográficas}

ABRAMOWICZ, Anete. O direito das crianças à educação infantil. Pro-Posiçōes, Campinas, v. 14, n. 3 (42), set./dez., 2003.

AGAMBEN, Giorgio. Infância e história: destruição da experiência e origem da história. Trad. Henrique Burigo. Belo Horizonte: Editora UFMG, 2005. 
ARENDT, Hannah. A condição humana. Trad. Roberto Raposo. Rio de Janeiro: ForenseUniversitária, 1987.

BAUMAN, Zygmunt. O mal-estar da pós-modernidade. Trad. Mauro Gama e Claúdia Martinelli Gama. Rio de Janeiro: Jorge Zahar, 1998.

BENJAMIN, Walter. A obra de arte na época de suas técnicas de reprodução. In: Ospensadores. São Paulo: Abril Cultural, 1975.

. Reflexões: a criança, o brinquedo, a educação. Trad. Marcus Vinícius Mazzari. São Paulo: Summus, 1984.

. Obras escolhidas III. Charles Baudelaire. Um lírico no auge do capitalismo. São Paulo: Brasiliense, 1994.

. Reflexôes: a criança, o brinquedo, a educação. Trad. Marcus Vinícius Mazzari. São Paulo: Duas Cidades; Editora 34, 2005.

BONDIOLI, Ana. Manual de educação infantil: de 0 a 3 anos - uma abordagem reflexiva. Trad. Rosana S. Di Leone e Alba Olmi. Porto Alegre: ArtMed, 1998.

BONDIOLI, Ana. (Org.). O tempo no cotidiano infantil: perspectivas de pesquisa e estudo de casos. Trad. Fernanda L. Ortale e Isle Paschoal Moreira. São Paulo: Cortez, 2004.

BOURDIEU, Pierre. A economia das trocas simbólicas. São Paulo: Perspectiva, 1987.

. Escritos de educação. Petrópolis: Vozes, 1998.

BROUGÈRE, Gilles. A criança e a cultura lúdica. Revista da Faculdade de Educação. São Paulo, v. 24, n. 2, jul./dez., 1998.

CASSIRER, Ernst. Las ciencias de la cultura. Trad. Wenceslao Roces. México: Fondo de Cultura Económica, 1993.

. Ensaios sobre o homem: introdução a uma filosofia da cultura humana. Trad. Tomás Rosa Bueno. São Paulo: Martins Fontes, 1994.

CASTELLS, Manuel. A sociedade em rede. São Paulo: Paz e Terra, 1999.

CHOMSKY, Noam. A lingüistica cartesiana: um capítulo da história do pensamento. Trad. Franscico M. Guimarães, Petrópolis: Vozes; São Paulo: Editora da Universidade de Brasília, 1972.

CORSARO, William A. Le culture dei bambini. Bologna: Editrice il Mulino, 2003.

ECO, Umberto. Apocalípticos e integrados. São Paulo: Perspectiva, 1970.

ELIAS, Nobert. O processo civilizador. Trad. Marcus Vinícius Mazzari. São Paulo: Summus, 1984. v. 1.

ELIAS, Nobert e SCOTSON, John L. Os estabelecidos e os outsiders: sociologia das relações de poder a partir de uma pequena comunidade. Trad. Vera Ribeiro. Rio de Janeiro: Jorge Zahar, 2000. 
FERNANDES, Florestan. As “Trocinhas” do Bom Retiro: contribuição ao estudo folclórico e sociológico da cultura e dos grupos infantis. Pro-Posiçôes, Campinas, v. 15, n. 43, jan./abr. 2004.

GARCÍA CANCLINI, Néstor. Culturas híbridas: estratégias para entrar e sair da modernidade. São Paulo: Editora da Universidade de São Paulo, 2000.

GOFFMAN, Erving. Representaçôes do Eu na vida cotidiana. Trad. Maria Célia Santos Raposo. Petrópolis: Vozes, 1985.

HELLER, Agnes. O cotidiano e a história. Trad. Carlos Nelson Coutinho e Leandro Konder. São Paulo: Paz e Terra, 2004.

HELLER, Agnes e FEHER, Ferenc. A condição política pós-moderna. Trad. Marcos Santarrita. Rio de Janeiro: Civilização Brasileira, 2002.

HENGST, Heinz e ZEIHER, Helga (a cura di). Per una sociologia dell'infanzia. Trad. Laura Gobbi. Milano: FrancoAngeli, 2004.

JOBIM e SOUZA, Solange (Org.). Subjetividade em questão: a infância como crítica da cultura. Rio de Janeiro: 7 Letras, 2005.

MARTIN-BARBERO, Jesús e REY, Germán. Os exercícios do ver: hegemonia audiovisual e ficção televisiva. São Paulo: Editora SENAC São Paulo, 2001.

MARTIN-BARBERO, Jesús. Dos meios às mediaçôes: comunicação, cultura e hegemonia. Rio de Janeiro: Editora UFRJ, 2003.

NOGUEIRA, Cláudio Marques Martins e NOGUEIRA, Maria Alice. A sociologia da educação de Pierre Bourdieu: limites e contribuições. Educação e Sociedade. Campinas, ano XXIII, n. 78, abr. 2002.

PAIS, José Machado. Vida cotidiana: enigmas e revelações. São Paulo: Cortez, 2003.

PINTO, Manuel. A televisão no quotidiano das crianças. Porto: Afrontamento, 2000.

QUINTEIRO, Jucirema. Sobre a emergência de uma sociologia da infância: contribuições para o debate. Perspectiva, Florianópolis, v. 20, especial, 2002.

. Infância e educação na sociologia: questōes emergentes. In: Sociologia para educadores-

2. O debate sociológico da educação no século XX e as perspectivas atuais. Rio de Janeiro: Quartet, 2005.

QVORTRUP, Jenz. I bambini e l'infanzia nella strutura sociale. In: HENGST, Heinz e ZEIHER, Helga (a cura di). Per una sociologia dell'infanzia. Trad. Laura Gobbi. Milano: FrancoAngeli, 2004 .

SARLO, Beatriz. Paisagens imaginárias. Trad. Rubia Prates e Sergio Molina. São Paulo: EDUSP, 1994.

SETTON, Maria da Graça Jacintho. Família, escola e mídia: um campo com novas configurações. Educação e Pesquisa, São Paulo, v. 28, n.1, jan./jun. 2002. 
Um novo capital cultural: pré-disposições e disposições à cultura informal nos segmentos com baixa escolaridade. Educação e Sociedade, Campinas, v. 26, n. 90, p. 77-105, jan./abr. 2005.

ZEIHER, Helga. Costruire generazioni nella quotidianità domestica. Scuola e Città. Milano: La nuova Italia Ed., v. 5, n. 4, 2003.

ZILBERMAN, Regina (Org). A produção cultural para a criança. Porto Alegre, Mercado Aberto, 1984. Série Novas Perspectivas.

Recebido em 26 de outubro de 2007 e aprovado em 13 de junho de 2008. 